casionally for crystals. If no crystals are found in an acid specimen of urine of an average specific gravity then the abnormality may be neglected.

(2) Cystinurics who habitually pass crystals should be advised to keep the urine dilute by large fluid intake, and to live on a vegetarian or a lowprotein diet. The crystals can generally be made to disappear from the urine if sufficient alkali is given by the mouth, but the amount required is likely to be greater than a patient could tolerate for more than a short spell. Anyhow, prolonged alkalinization is not necessary because most cystinurics who are careful about their diet and fluid intake succeed in avoiding calculous disease.

(3) Once renal calculi have formed surgical treatment is necessary. Fortunately the disease is often unilateral and the patients are in good condition for operation. After surgical removal of a cystine calculus another may form later in the kidney, so the patient needs to be kept under supervision. Cawker (1946) advises that after removal of cystine calculi from the kidney recurrence may be avoided by adopting, for one week in each month, a low protein diet with sufficient alkali by mouth to keep the urine alkaline. He says that this not only prevents crystallization of cystine but will actually dissolve a small cystine calculus. This is worth trying, but there is little evidence that cystine calculi can be dissolved by keeping the urine alkaline. Alkalinization of the urine merely prevents the deposition of crystals; it does not diminish the excretion of cystine nor dissolve stones which have already formed.

\section{BIBLIOGRAPHY}

BRAND, E., BLOCK, R. J., and CAHILL, G. F. (1937), F. Biol. Chem., I19, 681 .

CAWKER, C. A. (1946), Canad. M. A. F., 55, r9.

DUKES, C. E. (r95I), 'Brit. Encyclop. Med. Pract,' and Ed. (Butterworth), in the press.

LEWIS, H. B. (1932), Ann. Int. Med., 6, 183.

MELVIN, P. D., and ANDREWS, J. C. (r937), $\mathscr{F}$. Urol., 37, 655. REMANDER, A. (1937), Acta Radiol., 18, 807.

\title{
THE RIDDLE OF GENERAL PRACTICE
}

By C. J. L. Wells, M.A., M.B., B.Ch. Oxon.

General practice has been brought into the forefront of medical politics (and I am extremely glad that this has happened) by, without question, the publication of the Collins' Report and two B.M.A. Reports, the one on the training of the general practitioner and the other on health centres. Collins, as you know, was an individual from the colonies investigating alone and at the request of the Nuffield Foundation. 'He describes in a long report of 40,000 words his surprise and distress at what he saw, wondering in his more pessimistic moments whether the sinking ship which was general practice was capable or even worthy of salvation, and finally concluding that it was and that it must be saved. The B.M.A. Committee on general practice and the training of general practitioners consisted of 32 members of which, as far as I could make out, not more than one-third were general practitioners. It sought to plot the path from the 'Slough of Despond' in which it found general practice forward to the 'Delectable Mountains.'

The Collins' Report filled me with the utmost gloom partly because of its conclusions, and partly because those conclusions were so sincerely held. My mind went back to Brett Young's descriptions of industrial practice before the 1913 Act, in such books as 'Dr. Bradley Remembers' or 'Brother Jonathan,' and it appeared from the conclusions. of the report that what was true then remains true to this day and with even heavier emphasis. That his standard of what is good practice and what is bad was not my own had nothing to do with my gloom; it was the widespread degredation of medicine that he depicted which was as shocking as it was incredible. The report is not true of innumerable general practices any more than Cronin's 'The Citadel' depicts accurately the average inhabitants of Harley Street.

The B.M.A. Committee's Report on general practice and the training of the general practitioner produced an entirely different impact. I was reminded of the Pilgrim's progress as he journeyed to the Celestial City and of all the trials and tribulations through which he had to pass before he arrived at that desired haven. Much of it I felt to be unpractical and idealistic in a severely practical and far from ideal world. I wondered much if the gentlemen of the B.M.A. could not have plotted a simpler path and envisaged a simpler traveller.

The report on health centres was to me infinitely 
the best balanced of the three and I felt at home and, to a large extent, in agreement with nearly everything that was written in it, largely, no doubt, because the majority of the members of that Committee were clean-bred general practitioners of good standing.

.These reports, especially the Collins' Report, produced an immediate response in the medical and lay press. A leading article in The Times stated that "If general practice is not raised to a new level of competence, some would say restored to its rightful place, the whole of medicine will suffer,' and again from another source, 'Of all the problems besetting the medical profession today in its desire to provide the population with the best medical care, that of restoring the family physician to a position commensurate with his contribution to society by improving the standards of general practice appears to be the most pressing.' Both these passages suggested that all was not well with general practice, that a deterioration of the practitioners' work and prestige had taken place and that what Osler described as "That flower of our profession, the cultivated general practitioner,' was in grave danger of fading. This is certainly suggested in individual letters in the medical press, certain writers going so far as to deplore the deterioration of their own services. There are further signs, fathers are advising against their sons entering general practice because they find present conditions in practice humiliating if not intolerable, and the newly-qualified are found searching anxiously for openings in other fields of work.

This position has been greatly accelerated by the coming of the new Act although certain aspects of general practice had been felt to be unsatisfactory prior to this time. As I remember it, the most popular cry against general practice before the coming of the Act was the exacting nature of the work, the strain of being on constant call, the increase in the amount of non-medical and paper work, the encroachment and unsatisfactory nature of outside clinics, and the peculiar antics of the examining medical officers. If these were legitimate grumbles under the old Act, what of the new-'Whereas your yoke was heavy I will add to your yoke and whereas your fathers scourged you with whips I will chastise you with scorpions.' How true! The heavy increase in non-medical and paper work, the increase in trivialities, and a deep distaste of the bands of ministerial control have caused work which was always exacting - to become irksome if not intolerable. But there is another and, I believe, a far more important side of the question which must not be overlooked and that is the fragmentation of the responsibility previously exercised solely by the family doctor for the welfare of his patients. Immediately this fragmentary process takes place and responsibility is divided between the clinic, the hospital, the health visitor, the almoner, the paediatrician, the midwife and the specialist, then heaven help the patient and heaven guide the stumbling footsteps of the poor general practitioner. Whenever division of responsibility occurs in this way interest in the personal aspect and even in the clinical condition of the patient is largely extinguished and service of necessity deteriorates. I do not for a moment believe that the restlessness of the general practitioner under the Act, blindly stupid as much of it is, is fundamentally a financial one. The question of adequate pay, that most indefinable of terms, comes increasingly to the fore as interest in work recedes into the distance; that unhappy and needless state of affairs is what has now overtaken us.

I think I am correct in saying that in this city there are at least eight Medical or Assistant Medical Officers of Health who control I 5 child welfare clinics weekly, five antenatal clinics weekly and five postnatal clinics monthly, not to mention immunization and vaccination clinics. This structure is further supported by 18 health visitors as well as almoners and welfare officers. All these excellent busybodies are, in fact, carrying out and even interfering with what should be the normal duties of the general practitioner, and none of it is work that could conceivably be considered to require training at specialist level. It is no answer to say that some of these clinics are manned by general practitioners especially in the rural areas. What right has any doctor, general practitioner or otherwise, to interfere with the patients of another doctor unless he is specifically requested to do so? If a doctor is not willing or capable of looking after his patients then he should lose them to someone who is, and not be tempted to shelter under the protective umbrella of a clinic. Is it not obvious that this whole system undermines the doctor-patient relationship which is the foundation of family practice? What is the result when the advice of the clinic runs counter to that of the family doctor and the patients' loyalty to the one is pitted against their loyalty to the other? What indeed?

I have heard the term doctor-patient relationship scoffed at and I have been asked 'What does this vague expression embrace? What valuable intimacies are so mysteriously vouchsafed to the family doctor and hidden from the world at large and in any case of what are their medical value?

Only these. The general practitioner lives among his people, he knows their habits of life, he knows their families, the inside of their homes, their virtues and their shortcomings, their hopes 
and their fears. He sees them unmasked in illness and masked in health, he knows the cowards and he knows the heroes. I am not talking sentiment, I am merely stating hard and often extremely unpleasant fact. I will go further. The diagnosis of nine-tenths of his patients' functional disorders is presented to him on a plate and often enough the causes of their organic disease. To quote Ryle, - There are eyes without a microscope, ears without a stethoscope, and wits without chemistry and radiology.' These are his and no clinic system or specialist service can adequately replace them. The doctor-patient relationship should not be preserved as a perquisite of the well to do and denied to the poorer classes, but this is rapidly becoming the case.

What has impressed me of late, much more deeply than previously, is the fact that general practitioners are the only section of the profession who practice the art of medicine in anything like the full sense of that word. There is a great tendency at the present time in this country to increase both the number of specialists and the number of specialities. The body is divided and subdivided and each subdivision claims its band of specialists which, I understand, is described as knowing more and more about less and less, but I believe that the increase in real knowledge gained by, such methods is small when compared with the loss of a wide and sound judgment which it so often entails.

If in cricket you had a man with only one stroke that he could play, possibly with masterly skill, who was nearly useless in all other departments of the game, which did not even particularly interest him, it is doubtful if in any true sense he could be called a cricketer. He would be an even more difficult person to place if he insisted that he was the only person qualified to score off that particular stroke, as he played it all day long whereas other people were only playing it as part of a number of other strokes and therefore could not in his opinion be considered to play it efficiently. He might go even further and evolve a number of complicated techniques which would convert what was always considered a comparatively simple proceeding and within the competence of any reasonably good cricketer into a manœuvre that he alone could attempt. Such a person would be unbalanced in his judgment which, if followed, would go a long way towards destroying the essentials of the game. And so it is with medicine.

The Americans, having discovered the error into which general medicine can fall through overspecialization and the lack of a balanced outlook it can produce are, at the moment, attempting to reclaim from us the vision of general practice and the doctor-patient relationship which they have lost. We, with perplexing perversity, are striving to follow in the footsteps they are now seeking to retrace.

Theoretically, to plan medicine so that all groups of disease are treated by specialists in that particular group, might appear desirable. In practice this is not borne out, since all specialists, and this is in no way confined to medicine, tend to get their own speciality out of its true proportion. Surgeons become too prone to interfere, physicians too apt to see lions where only lambs exist, and all unconsciously twist pathology into their own special study. That is the result which manifests itself through the fragmentation of medicine but ' the body is not one member but many and if one member suffers then all the members suffer with it.' That is as true as it was 2,000 years ago and for good or for ill the general practitioner is the only person who sees the body as a whole. The very best men are wanted and are not too good for this entirely essential work, if the standard of medicine is to be maintained and enhanced. If you agree, and I feel that you must do so, how are the best men to be attracted? Before I speak on that, may I point out quite clearly how you will not do this. You will not do it attempting to extract the cream and interest from general practice by multiplying clinics run by health departments, the very creation of which suggests to the public the incompetence of general practitioners. You will not do it by removing. hospital beds from their care and handing their patients over to wandering consultants and specialists whose personal interest must of necessity be small as compared with their own, and you will not do it by converting the general practitioner into a finger post pointing feebly in every direction other than his own. What is the value of a six years' intensive training if at the end of it he is to undertake work deprived of all its solid medical interests and supercharged with drudgery? Not until the full weight of the responsibility for the care of his patients is squarely placed on his shoulders will you again attract the best men into general practice.

As a justification of these trends two lines of argument have been elaborated, which are to me unsound. The medical planners express deep concern that the general practitioner should be tempted to tackle work 'outside his competence,' a loose phrase typical of many in common use today. In this connection it can at once be pointed out that errors of judgment and technique cling to a general practitioner, who lives amongst his patients, far more tenaciously than to a consultant protected as he is by his status and grading; the fear of bad results makes it extremely unattractive for the general practitioner to attempt things out- 
side and, often enough, well within his competence. I wonder if the specialist is not more likely to attempt things outside his competence than the general practitioner is to attempt things outside his.

The second argument is that medicine and surgery have become, with the advance of science, so much more complicated that a wide increase in specialization has become necessary. Again I wonder if the exact opposite is not the truth. If you will grant that the complication of techniques does not necessarily denote spectacular advance, then the discovery of the antibiotics and the sulphonamides, blood transfusion, improvements in radiography and many other advances have simplified and not complicated many problems. Do not think for a moment that I disbelieve in the value of specialists; that would be entirely erroneous. I believe them to be an invaluable group, but I am deeply convinced that a high standard of general practice is more important to the public weal.

There is just one more thing on quite another subject to which I must allude. In my opinion there is no single measure in the new Health Act, riddled as it is with miscalculation, built as it is on false foundations, and directed as it is by clever and ignorant men, no measure more calculated to lower the standard of medicine than the abolition of the sale of practices. Gone to a large extent is the financial stimulus to group practice and the determination to plough back money into the increase of apparatus and the improvement of premises and amenities, in order to raise the standards of work and service. The satisfaction of doing better work must come first, but the result of better work must be reinforced by the financial rewards that better work should bring. Otherwise you are courting indifferent service, you are penalizing success and condoning failure, which is, to me, one of the most glaring and fundamental errors of the so-called security state. Let me remind you of the words of the first Lord Brougham:

' It behoves us to think well and long and anxiously and with all circumspection and with all foresight, before we thrust our hands into a machinery which is in such constant and rapid action. For if we do so in any way incautiously we shall occasion ourselves no little mischief and may stop that movement which it is our wish to accelerate.'

What beautiful dignity of expression ! If the planners of the Health Act had been made to repeat these words every night on going to bed and again when shaving in the morning, half the blunders of the Act would never have been committed.

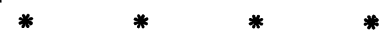

All riddles are said to have answers, though not necessarily simple and not always complete as were the answers to the riddles of our childhood. The riddle of general practice will not begin to be solved until the following steps have been taken: (I) The wide establishment of group practice with fully-equipped central surgeries; (2) The return and extension of general practitioner hospitals and general practitioner beds; (3) the abolition of clinics not requiring specialized knowledge; and (4) The freedom to buy and sell practices.

Group practice holds many benefits and advantages, both for the patient and the practitioner. From the patient's point of view there is a wider choice of doctor within a firm, and there is always the opportunity for them of obtaining a second opinion without delay from another member of the firm who they probably already know and by whom they are known. Further, it is possible and indeed convenient for each partner to work up a special line of medicine or surgery in which he is himself specially interested as a strong point, and in this way again the confidence of patients is greatly increased. From the existing practitioners' point of view, the periodic entrance of new blood helps to disseminate new medical and scientific knowledge, while in return the newcomer is guided by experienced hands along the highways and byways of general practice. A second ad vantage is an economic one. It is far mores economical for three or four doctors in partnership to have a common central surgery than the same number not in partnership to have separate surgeries. Clerical staff, nursing, receptionist facilities and apparatus can in this way be indulged in, the expense of which could not be borne by any single member. Such central surgeries, many of which of course exist already, are the prototype of the health centres envisaged in the Act. Here the poor planners, suffering from a smartish attack of the 'delusions of grandeur,' have only approved plans for centres the cost of which lies between $£_{1} 50,000$ to $£_{200}, 000$, with the natural result that this promised step has now been indefinitely postponed. The iniquity of the political jobbery to which the profession has fallen a prey is that, built at reasonable cost, such premises especially in the poorer areas would have raised the standard of medical practice more than any other single thing. A third advantage of group practice is that leave of absence for study or holidays, both of which are essential, can be more adequately and easily arranged.

There will always be doctors who prefer, and are more suited, to work alone, as there will always be patients who prefer to know one doctor and none other. There will always be a place for him but it may be difficult to attain to the full 
standard of the all-round efficiency of the partnerships, especially if he be placed in the isolation of the country. I would encourage group practice even if it extended no further than a working understanding between practitioners working singly, more especially in the rural areas, but also in the county town and even in the city itself.

The next point is the return of all hospitals previously staffed by general practitioners. It is only in this way that practitioners, with the facilities available only in a hospital, can assume the full responsibility for their patients and obtain the fullest satisfaction of medical work. It is only in this way that you will attract into general practice the highly-qualified graduate now battering, so often in vain, at the gates of consultant practice. In these hospitals such men should be given a key position on the staff suitable to their special qualifications, an appointment which will be made more balanced, more human and of greater value to the community as it rests on the broad foundations of general practice. This is a matter of infinite importance because at its foundation lies, in reality, a cleavage of view within the profession itself and on its decision depends the rise or fall of the standard of general practice.

I am not, hor would any thoughtful person be, hostile to a sort of medical hierarchy who would deal with and seek to unravel for us the deeper mysteries of medicine and surgery. Such is and must always be entirely desirable and necessary, but when one sees an attempt by specialists to elevate specialization far above its true position and to debase general practice, when attempts are made to prove the part greater than the whole, then one cries with Israel of old, 'You take too much upon you, ye sons of Levi.'

Now I will refer to clinics. I believe that theoretically no clinic should be established unless its object is the carrying out of work of a specialist nature, and work outside the competence of the general practitioner. What clinic does this? I know of none. What reasonably well-educated general practitioner is not capable of carrying out his own antenatal, natal and postnatal work, guiding the welfare of children, carrying out such things as immunization with skill equal to that emanating from the local Medical Officer of Health's departments? As I have pointed out, what can be more unsatisfactory than splitting responsibility in this way? Not infrequently the patient falls between two stools, and it is then for the general practitioner to redeem the position. If these individuals wish to enter front-line work let them enter into it properly and not dally round the edge interfering with those who must bear the heat of the day. These well-meaning organizations do an incredible amount of harm to general practice and too often impede those movements which it is their wish to accelerate. Are these hard words? They cannot be to those who realize the vital necessity of a first-class practitioner service, and believe me that, when I say that, I am not putting up a defence for a class to which I have the honour to belong but because, as I view the wide field of medicine, I can come to no other decision and can with honesty form no other conclusions.

I have already stated my opinion of the serious effect of the veto on the sale of practices and I need add no more other than to quote Alfred Cox, who was for so many years secretary of the B.M.A. "I believe our Citadel as a "free profession" was. surrendered when it was accepted that every general practitioner entering the Service must sell his practice to the State.' This was an absolute tragedy which has had its repercussions, through our action, on so many other free societies of men and has placed liberty itself in jeopardy. What of the future?

One day, perhaps quite soon, a Government driven mad by the vast, mounting and wasteful expenditure which has resulted from forcing political views for political ends and against all the advice of a society of men and women bred to a high degree of disinterested service, will come hat in hand to the profession and ask what it must do to be saved. Then we must be prepared to meet it, not with a body of pseudo-political, pseudomedical bargaining negotiators, but with men determined to know nothing save of the highest standards of medicine and of service to mankind. Take heart.

One more thing and I have done. People are at this time commemorating the centenary of Robert Louis Stevenson's birth, and this has reminded me of his beautifully worded 'Dedication.' 'There are men and classes of men that stand above the common herd. The soldier, the sailor and the shepherd not infrequently, the artist rarely, the physician almost as a rule. He is the flower (such as it is) of our civilization, and when that stage of man is done with and only remembered to be marvelled at in history, he will have been thought to have shared as little as any in the defects of the period and most notably exhibited the virtues of the race. Generosity he has, such as is possible to those who practice an art, never to those who drive a trade ; discretion, tested by a hundred secrets, tact, tried in a thousand embarrassments. and, what are more important, Herculean cheerfulness and courage. So it is that he brings air and cheer into the sickroom and often enough, though not so often as he wishes, brings healing.'

If anyone had a right to describe the merits or 
otherwise of the profession I suppose it was poor Stephenson with his lifetime of ill health, but when I first read it, it struck me as so adulatory that, to say the least of it, it would be a little difficult for the average doctor to hang it on his own wall. As the years rolled on I began to realize that Stevenson was only expressing what were the sentiments of a large section of the community towards their own doctors, and it was an intensely sobering thought.

\section{PAIN IN MALIGNANT DISEASE
By Stanley Way, M.R.C.O.G. \\ Gynaecologist, Newcastle Regional Cancer Organization; Associate Surgeon, Gynaecological Department, Royal Victoria Infirmary, Newcastle-on-Tyne}

Pain is seldom encountered as an early symptom of carcinoma of the uterus, but in advanced and recurrent cases, especially in carcinoma of the cervix, it is an extremely common symptom and one which frequently calls for treatment in the later stages of the disease.

\section{Types of Pain}

It is usual to differentiate between the two main types of pain in carcinoma of the uterus (a) visceral and (b) somatic. These types of pain have a different aetiology and call for very different types of treatment.

\section{Visceral Pain}

Visceral pain is so called because it is referred to the pelvic viscera and is chiefly referred to the bladder and the rectum. It is experienced when either of these organs is involved by direct extension of the tumour, or it may be due to radium necrosis if radium has been employed in the treatment of such a case. It is frequently difficult to distinguish between radium necrosis and recurrent tumour, but obviously from a prognostic viewpoint it is essential to do so.

\section{Rectal Pain}

The complaint of rectal pain in a patient who has been treated for a carcinoma of the cervix by radiotherapeutic measures should immediately arouse the suspicion of radium necrosis. Involvement of the rectum with tumour, even in late stages of the disease, is not common, but irradiation injury to the rectal mucosa is the most common manifestation of radium necrosis and some form of rectal disturbance occurs in probably as many as 8 per cent. of cases of carcinoma of the cervix treated with radium. Todd, in 1938 , drew attention to this disorder, which he called ‘ pseudocarcinoma of the rectum,' and he believed that it was due to over irradiation of the parametrial triangle. In some cases he believed it was due to slipped vaginal applicators or to retroversion, for in this latter case the uterine tube is brought close to the rectum and may increase the dose of irradiation by as much as 20 per cent. The onset of the disease may be noticed a few days or weeks after the completion of radium treatment, when the patient suffers from a mild proctitis with diarrhoe\& and tenesmus. If the necrosis progresses de faecation becomes exceedingly painful, there is constant tenesmus and these patients are unable tợ. sit with comfort and frequently have localized pain in the perineum and anal region, accompanied by the passage of mucus and slime. Vaginal examination reveals a typical area of rubbery thickening in the posterior fornix, and rectal examination shows an ulcer on the anterior rectal wall behind the cervix. Bleeding is always present but is usually slight; occasionally very severe haemorrhage from the rectum takes place.

Treatment. If the necrosis is mild and the pain not too severe, astringent enemata such as tannic acid may considerably relieve the discomfort, but if it progresses it is a clear indication for presacral neurectomy. Colostomy is not indicated for the relief of pain and is only necessary if a very large recto-vaginal fistula occurs, or if a rectal stricture completely occludes the bowel.

\section{Bladder Pain}

The mucosa of the bladder is more resistant to the effects of irradiation than that of the rectum, and furthermore the bladder is much more fre- 0 quently involved by local spread of the carcinoma of the cervix than is the rectum. Pain referred to the bladder is, therefore, often of more serious import than pain referred to the rectum. Some degree of cystitis is extremely common after radium treatment of carcinoma of the cervix, and 